\title{
Investigating university teacher practice: A need for didactics
}

\author{
Khaoula ELARIF, Salek OUAILAL, Bouazza EL WAHBI \\ Laboratory of Analysis, Geometry and Application, Faculty of Sciences, Ibn Toufail University, B.P :
}

133, 14 000, Kenitra, Morocco

khaoula.elarif@gmail.com, belwahbi@yahoo.fr

Regional Center for Careers Education and Training - Agadir, Morocco

Tarikati.math@gmail.com

\begin{abstract}
Based on his position as a mathematician teacher at the university, the first year teacher sees discipline as a rigid base. Therefore, without any teacher training program, he promotes teaching on learning, trying to impart mathematical knowledge without specific didactical teaching tools. In a vision to develop professional skills of a reflective practitioner, we conducted a survey for teachers to gather information about their teaching practice and didactical underlying issues. The results show a need for a didactic training on teaching at the university.
\end{abstract}

\section{Keywords}

Teaching at the university, professional skills, clinical teaching, reflexive teacher.

\section{Academic Discipline And Sub-Disciplines}

Education; Didactics of Mathematical Sciences

\section{SUBJECT CLASSIFICATION}

Innovation in education

\section{TYPE (METHOD/APPROACH)}

\section{Survey/Interview}

\section{INTRODUCTION}

Through attendance of a PhD thesis on didactics of mathematics, the remarkable absence of mathematics teachers was noted despite the fact that the event took place at the sciences faculty on Saturday morning. The sequence of the members of the jury's questions was rich from the didactic point of view, despite the "natural" disagreement on various points between experienced teachers and the speaker who is a teacher in high school. One of the conclusions of this debate recommends the multiplication of this kind of thesis work by professesional utility. On this subject, several questions arise, we will limit in a first section, to clarify one among others that we deem essential:

Is it enough to know mathematics to teach it ?

On the basis of this question we sought to identify state, and teacher practices that foster the improvement of educational practices. More specifically, we will try to give some insight of the dynamic aspect of the practice of mathematics and its teaching at the university, and clarify how these practices indirectly influence the quality of 
learning. In a second section, we will focus on the reality of the teaching of mathematics at the university. Indeed, along his academic studies the professor established with mathematical knowledge a relationship influenced by subjectivity (success, controversies, representations, ...). Consequently, the teaching operation is generally attributed to empiricism, which raises issues of coherence and presentation of courses delivered to students. To better understand the broad issue motivating this strand of our research, we used a mixed method. Qualitative data were provided by

individual interviews conducted with 16 teachers. While our analysis of them was explicitly guided by the framework described bellow. Our quantitative evidence consisted of responses collected from 57 university teachers during the second round of survey. we will present and analyze the results of questionnaire to capture the interactions between didactic process criteria on the one hand, and the action of mathematics beginner teachers on the other hand.

The broad focus of this study is to identify some convictions of teachers that could align teaching practice with the student learning. So we support the approach by clinical didactics (Terrisse, 1999) as a theoretical framework highlighting the personal history of the professor.

We aspire to analyze and understand the teaching practices to establish any possible relevance of processes of transmission and appropriation of mathematical knowledge.

Methodically, the device used refers to the framework known of Pedagogical Content Knowledge (PCK), let us note in passing that the use of these two theories: phrancofone (clinical didactics) and PCK insists on thinking about the question of complementarity of these research approaches in sciences and technology didactics.

The conclusion of the analysis of the data thus obtained promotes and supports the necessity of a didactic practice. A practice whereby we would like to renew some teaching practices often protected by the "institutional freedom" given to the university teacher.

\section{IS IT ENOUGH TO KNOW MATHEMATICS TO TEACH MATHEMATICS ?}

The teacher at the university has a dual mission. On the one hand, he has to produce new fundamental knowledge in the course of his research work (often on a specific axis of mathematics), which raises a question of mastering mathematical tools related to other specialties. On the other hand, he must transmit to the students knowledge and a certain mathematical know-how of which he is entirely the sole responsible. In this respect, questions of structure, coherence and objectives persist before a course is given, according to a tutorial classes (TC), already the word " tutorial " implicitly relates a goal!

However, the student complains about non-innovated courses often poorly organized and finds himself lost in front of a significant diversified amount of handouts and mathematical content, and when he comes to the assessment test does not know how to prepare for it. Sometimes even he refers to the students about the person the teacher - responsible for the proposal of the subject of examination instead of being interested in mathematical knowledge. This state of amalgamation and opacity further contradicts one of the purposes of the department of mathematics, namely precision and clarity in ideas and also in the training of scientific knowledge.

These personal initiatives and closed office work, without intentions of collaboration with the colleagues of the discipline and without discussion of situations arising from the profession, confirms that a fortiori the obtaining of a higher degree from the university can not grant professional competence to the act of teaching.

Thus, we will ask ourselves about the teaching strategies supposed to be the source of these encountered problems. A call to the didactic of university education is strongly solicited. More specifically, upstream of university 
studies. Although some teachers at the university underestimate the role that pedagogy can attribute for the communication of mathematical knowledge!

\section{TEACHING MATHEMATICS AT THE UNIVERSITY BETWEEN PLANNED AND REALITY : APPROACH BY CLINICAL DIDACTICS}

To give the reader a brief overview of academic detailing in our universities. We note that the typical requirements to become a higher education teacher of mathematics is to require a doctorate degree in order to teach. Without any training in teaching abilities, often, the first year teacher is responsible for teaching tutorial classes (TC) where the main mission is to work the exercises with students while the courses are assigned to an experienced teacher.

The teacher at the university has a dual mission. On the one hand, he has to produce new fundamental knowledge in the course of his research work (often on a specific axis of mathematics), which raises a question of mastering mathematical tools related to other specialties. On the other hand, he must transmit to the students knowledge and a certain mathematical know-how of which he is entirely the sole responsible. In this respect, questions of structure, coherence and objectives persist before a course is given, according to a tutorial classes (TC).

However, the student complains about non-innovated courses and finds himself lost in front of a mathematical content poorly organized, and when he comes to the exam does not know how to prepare. On the other hand, in basic skills such as mathematics, many university professors are disheartened by the quality of student work. This state of opacity contradicts one of the purposes of the department of mathematics, namely precision and clarity of scientific knowledge.

Thus, we will ask ourselves about the teaching strategies supposed to be the source of these encountered problems. A call to the didactic of university education is strongly solicited. Although some teachers at the university underestimate the role that didactic can attribute for the communication of mathematical knowledge ! Our hypothesis is that personal initiatives, without intentions of collaboration with the colleagues of the discipline and without discussion of situations arising from the profession, lead to the fact that the obtaining of a higher degree from the university can not grant professional competence to the act of teaching.

\section{A case of teaching practice at the university}

During breaks between course sessions or TC, teachers mention the student outcomes qualified as low, in addition some of them ask for quality teaching in the secondary institution. That is, we will go beyond the plaintive discourse between the two institutions (university and secondary) to identify a central question for this paper. A question - in our opinion - that contributes to another formulation of our problem: Does the university teacher know if there is a distance between what he plans to convey and what is really transmitted to the students?

\section{Interview with teachers}

Data for our analyses arise from interviews with a sub-sample of 16 university teachers newly recruited from different universities. We present a summary of responses of the teachers of mathematics survey. We looked for any trace or clue in his teaching practice in terms of planning or evaluation of mathematical knowledge. Here are his conclusions in a moment of truth presented in points:

- "The exercises is proposed by the teacher of course often an experienced teacher";

- "I have never had a meeting beforehand with him, for the copies of exercises I find printed in the department " ;

- "I make the same correction for six groups, the TC session is about 90 minutes, it takes place in a class with an average of 80 students ; 
- "During one term, three sets of exercises are corrected, each with about 9 exercises ;

• "To find out where the course has stopped, I ask the students " ;

- "In the majority of cases it is me who undertake to resolve of the proposed exercises " ;

- "When correcting most of the time, there is no mathematical discussion the majority is content to take passively corrected exercices " ;

- "The subject of examination is still under discussion within the department between those who offer a MCQ and others who refuse, finally seeing the mass of the student choose the MCQ" ;

- "Students are often disturbed about the choice of auxiliary books for preparation, some are content to swallow the answers to the exercises" ;

- "The students always ask me for the model exercises of the series without being interested in the mathematical contents" ;

- "The proposed exercises dont generally suffer from coherence difficulty, for example, even in a prescribed order "

;

- "Mathematical formalism remains one of the major problems for first-year university students ;

- "The use of mathematical logic tools : quantifiers and mathematical reasoning is very limited".

In a first stage of the assessment, This citations would reflect, then, that there is a real gap between the mathematical knowledge actually taught and the mathematics that the department has judged to have accomplished.

In relation to the question proposed at the beginning of this section. In the table below we propose to analyze some extracts of verbatim of first year math teachers which raise a richness from a didactic point of view; because they mask the peculiarities of the subject teacher. This observation confirms the conclusion of the preceding paragraph.

Table 1. Some teachers' verbatim extracts

Excerpts from speeches Comments

Speech 1:

"This generation of students does not provide enough time for serious preparation"

The subject teacher refers to his own, sometimes traumatic experience. He can not forget situations that have been traumatic for him as a student.

\section{Speech 2:}

"In a session of TC, for a good management of large group, I fill the whole picture by making the students work and also to avoid the questions and discussions
The subject teacher always tries to keep his "image of teacher" in the eyes of the students. He keeps a distance by sometimes masking his fear of not answering an 
that will hinder the progress of the session : everything is clear !"

\section{Speech 3:}

"In my opinion, it is appropriate in the course not to make demonstrations too formal but rather to exhibit more practical examples";

"In this chapter dont waste your time reading this paragraph but concentrate especially on typical exercises proposed in the series of exercises"

"We did what we had to do, bringing the results of the evaluation were disastrous ! ... The students must assume their responsibility they have everything in their hands. "

" I do not give the full score in the evaluations "
The subject determines the essential traits of the contents of mathematical knowledge which he proposes according to his own conception of mathematical objects or his representations of mathematical notions.

The subject teacher in his posture of "professor" qualifies the subject of examination as easy. He has also a very subjective convictions of evaluation.

In a second phase of assessment, the first-year university teacher, does not even have an idea of the written errors or shortcomings of students. For example, it does not intervene in the correction of multiple choice questions (MCQ). Moreover, the teaching procedure for mathematics is divided between two teachers: a more experienced teacher ensures the courses and a second one responsible for the sessions of TC. Therefore, the student is disoriented between two teaching approaches delivered by two different teachers of mathematics.

\section{Approach by clinical didactics}

The theoretical approach that seems relevant to our research is the one which provides analytical tools that allow us to have a teacher of the university who is assimilated to a reflective practitioner, who is the subject of a planning project for his teaching. In this perspective, the approach is supported by clinical didactics, which focuses on taking into account the articulation of the subjectivity of the teacher, in view of the transmission of mathematical knowledge through the teaching subject. It résults of such operation "another" knowledge characterized by the teacher's history.

The goal of the present article is to change the manner in which the instructor's thinks about his/her teaching and by using dissonance create the feeling that he/she is ineffective and therefore needs to make changes to meet the "scientific competencies target". Indeed, Through the clinical analysis, we hope to convince the university professor to admit the possibility that his teaching practice might be in dissonance with the scientific competences targeted. Consequently, open a parenthesis with the teacher by presenting conclusions to him so that he can make a monodialogue inside to better know himself to better teach. A didactic planning and management of mathematical resources is a relevant proposal to avoid any unexpected teaching.

Clinical didactics (Loizon, Margnes and Terrisse, 2008) considers that the knowledge taught is strongly influenced by the historical path of the teacher. We used the qualitative data were provided by individual interviews 
conducted with teachers to determine the significance and the relationship with the three fundamental tools for the analysis of teaching practice:

- " The impossible to bear " applies to traumatic experiences arising from the teacher's own history. These events will influence his way of passing on the mathematical knowledge to be taught. See speech example 1 (see Table 1).

- "The subject supposed to be known " is characterized by the gap between what the teacher foresees to transmit and what he really transmits See speech example 2 (see Table 1).

- " Didactic conversion " refers to the decisions made and the choices of the content of mathematical knowledge to be taught by the teacher. See speech example 3 (see Table 1).

The teacher of course is often the leader of the operation of teaching with some sort of "personal" planning. He proposes exercises (not innovated) for the session of TC and sometimes leaves this task within the reach of his colleague. In summary, our question about the reality of the knowledge transmitted requires a more serious remedy on the part of the university organization. This is an important factor which could convince the university to introduce of a professional development training module.

\section{METHODOLOGICAL APPROACH : " PEDAGOGICAL CONTENT KNOWLEDGE"}

Having deep knowledge of mathematical knowledge is certainly necessary, but not enough to teach mathematics. There must be some connection between mathematical resources and mathematical knowledge teach to the student. However, the complexity of the nature of the the said process raises the question of the methodological device for carrying out a scientific study giving a valid synthesis, despite the aspect of the representativeness of the teaching population. Indeed, the subject maintains a game of private relation with knowledge, the didactic subject makes decisions in a space of freedom that it is allowed to be influenced. This position requires whether to revisit certain concepts that clinical didactics can illuminate. Our study engaged an exploratory research design.

Hence the need for a theoretical framework that which presents tools of analysis referring to the actions of the teachers by organization of the multitude of data relating to this deductive analysis mode. By antropological approach of didactics, the theoretical framework in which we place ourselves uses a concept is "pedagogical content knowledge" (PCK) (Lee Shulman, 1986).

At a conference held in October 2012 on the concept of PCK, there was a consensus among educational researchers around the definition of the term PCK:

"PCK is defined as a personal attribute of a teacher and is considered both a knowledge base and an action" (Gess-Newsome \& Carlson, 2013).

We briefly present in the following paragraph the elements of this concept that we will implement for our purpose in the rest of our work.

\section{Theoretical Framework}

The collection of documentation of teachers' professional teaching knowledge is inspired by the concept of PCK which is interested in the analysis of the gap between mathematical knowledge and pedagogical knowledge of the teacher. This concept provides a relevant tool as Kind (2009) says:

"There is strong evidence that PCK is a useful concept and tool for describing and contributing to our understanding of teachers' professional practices". Kind 
Indeed, Shulman (1987) classifies this knowledge into three categories: Subject Matter Knowledge (SMK), subject knowledge, Pedagogical Content Knowledge (PCK) and knowledge of the curriculum. As part of our work we will limit ourselves to the first and the second aspect of this knowledge, namely SMK and PCK.

The teacher in university is primarily interested in SMK characterization, while excludig the PCK. Mathematical knowledge and "mathematical competencies target" are taught separately. For example, sometimes the teacher writes on the board a demonstration sequence containing a subdivision of type " ", reflecting the idea that there is a second proposal that involves another " ". This practice teaching promotes learning demonstraions but not the how-to demonstrate. The status one hopes to find a mathematics teacher, not a person a well trained in mathematics in mathematics.

Several reviews of Shulman's (1987) idea about the process of transformation of mathematical knowledge (Hashweh, 2005; Burn, Childs, McNicholl, 2007; Park \& Oliver, 2008) took into account four phases of the didactic process. These phases explain the process of transforming the contents to be taught, knowledge: representation, interpretation, design of learning environments and adaptation to student characteristics. We propose to put in the table below, this teacher knowledge in three dimensions. The aim is to take up these aspects again, to identify the characteristics of teachers' personal relationships at university, through the questionnaires whose analysis constitutes the following paragraph.

Table 2. Criteria Considered in the Questionnaire

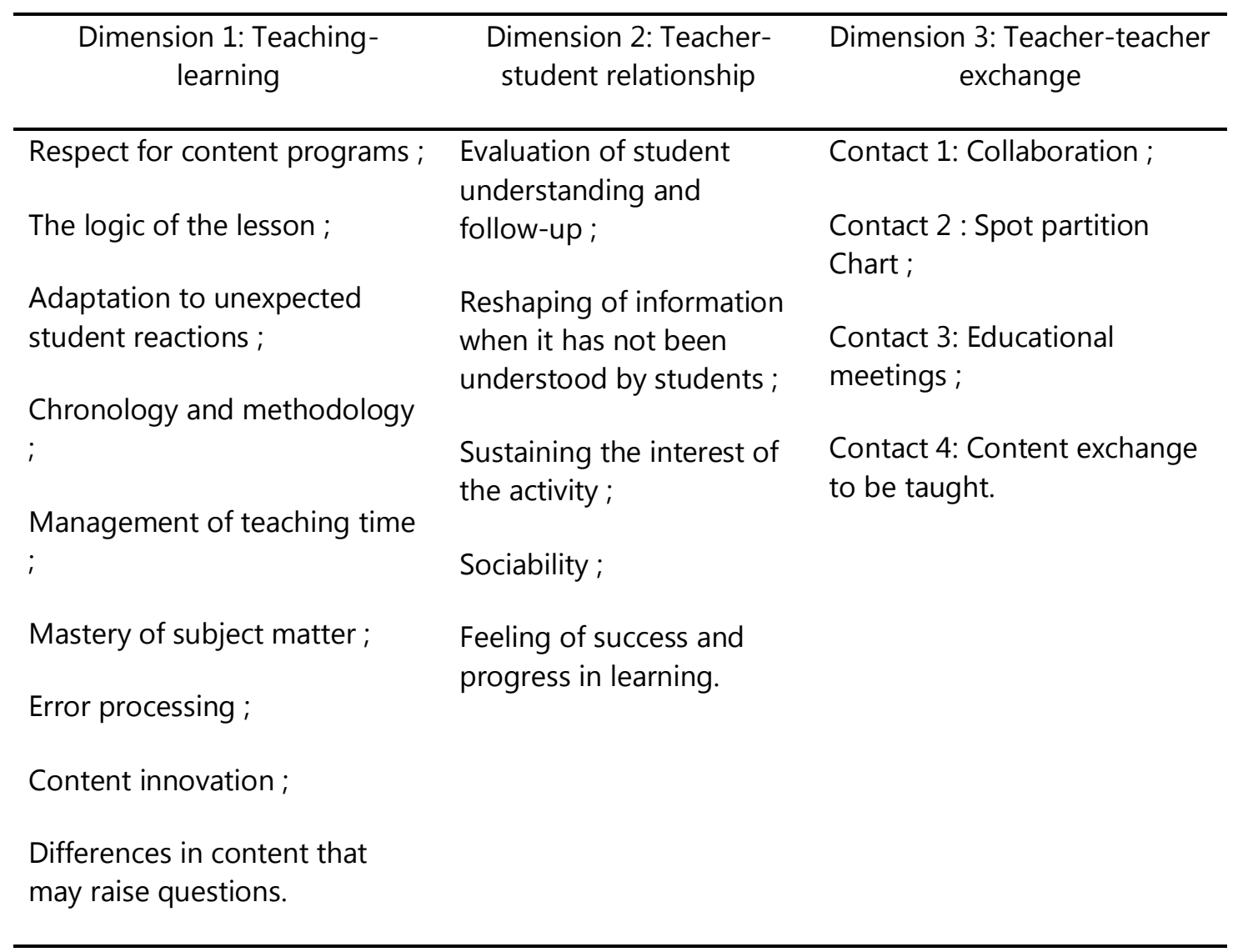

\section{DRAFT STATE OF THE ART OF CURRENT UNIVERSITY EDUCATION}

Over the last six years, the university has seen remarkable changes in the number of teachers recruited. For example, according to the 2014 report on human resources in the Ministry of Education, there were 13 contests for 
the recruitment of higher education teachers, for a total of 314 posts. Without training in education, the candidate in the recruitment competition is most often left to himself to dictate a list of contents to large groups. Without methodological guidelines. This change in the posture of a mathematical researcher - usually in a specific specialty - to a general mathematics teacher, requires a self-directed construction effort, rather than focusing on reflections likely to develop skills of students. This role-play, similar to a theatrical scene, is naturally legitimate because the latters are placed in a non-habitual domain of which they is not the master. In the strictest sense, who reproduces the strategies he was confronted with during his school career as much as a student when the image of a "model" teacher is clear in his mind!

This observation, however, has aroused our interest in the practices of budding teachers. For as we shall conclude later, these acts reduce the operation of teaching to the effective management of student groups. While trying above all to chase the time, either by making the students work to the maximum by taking notes or by a ceaselessly diction of the mathematical contents. As a result, questions about teaching practices persist, particularly for the teaching process: is it a matter of successfully completing the disciplinary program prescribed by the department or working on the quality of learning and training of students?

\section{The questionnaire for teachers}

To draw up an inventory of the current situation of the university teacher practice. We questioned novice teachers for a better identification of the situation on the one hand, and for sensitizing them to the need for didactic planning on the other hand, for the relevant management of a course leading to a learning. Thus, as Appendix explains in more detail, we proposed a questionnaire containing 26 questions which can be organized according to three dimensions ranked according to the interest imposed by our problem :

- A first dimension concerns the teaching-learning operation (12 questions);

- A second on teacher-teacher exchange (4 questions);

- And finally a third dimension around the teacher-student relationship (4 questions).

The first two introductory sections (5 questions) concerning the attributes of teachers (enlightenment, conceptions of teaching) and a second in conclusion containing a single question in which the teachers were asked about the didactic need, namely :

Question 26: If we can call didactics the study of the issues underlying all these questions, do you believe that before practicing the profession of teacher, that a training in didactics of the discipline is :

\section{Necessary $\quad$ 2. Not necessary $\quad 3$. Desirable}

\section{A posteriori analysis of the teacher questionnaire}

We administered the second round of surveys from January 2017, to June 2006. The targeted population of beginning teachers was contacted during the coffee break of a national mathematics research meeting, while asking participants to pass the questionnaire to their colleagues in the institution. We field tested our survey in 12 universities. Most of the answers that have been proposed are of a closed choice in two modes of answers : Yes or No.

Methodologically, we designed the questionnaire by the statistical processing software Sphinx Lexica. Thus, out of 73 questionnaires, 56 questionnaires(covering eight institutions of higher education) were returned and the analysis of the data shows a wealth of questions leading to problems concerning the practices of the activity at the university. 
We present a descriptive analysis and then a factorial analysis in two paragraphs, in diagrams or summary tables containing most of the statistical results concerning our problem.

\section{First descriptive analysis}

In a first reading, almost all (92\%) are in charge of teaching undergraduate university students, $75 \%$ of which are not satisfied with the conduct of such sessions. The a posteriori analysis is generally in conformity with our prevision that a formation in didactic of the discipline is appreciated by confirmation of more than $82 \%$.

According to the table below, the dimension "Teacher-student relationship", where the questions are coded in two modalities, receives the lowest degree of agreement (18\%). " students are supposed to look for me.. " claims a respondent.

Table 3. The most cited modality in the "Teacher-student relationship" dimension

\begin{tabular}{|lc|c|}
\hline Teacher-student relationship & \multicolumn{2}{|c|}{ Modality cited in $\mathrm{n}^{\circ} 1$} \\
\hline Encouraging students & No $: 47$ & \\
Stimulating students' interest & No $: 44$ & $\begin{array}{c}\text { Of } 56 \\
\text { observations }\end{array}$ \\
Encouraging Student Research & No $: 49$ & \\
Remedying student errors & No $: 46$ & \\
\hline
\end{tabular}

The second dimension "Teacher-teacher relationship" is timidly revealed (39\%), the following writings have been collected in this respect: "The lack of mass, the task of timetables, the research attribute and the particularities of the teaching subject : pride and sociability. "

This dimension can be synthesized according to the responses of the four variables (see Table 1) associated with the questions related to this part. It is then concluded from the summary table below that the clear majority of teachers do not benefit from exchanges between them, that could improve the teaching practice.

Table 4. The most cited modality in the "Teacher-teacher exchange" dimension

\begin{tabular}{|lc|c|}
\hline Teacher-teacher exchange & \multicolumn{2}{l|}{ Modality cited in $\mathrm{n}^{\circ} 1$} \\
\hline Contact 1 & No: 35 & \\
Contact 2 & No: 52 & $\begin{array}{c}\text { Of } 56 \\
\text { observations }\end{array}$ \\
Contact 3 & No : 48 & \\
Contact 4 & No: 35 & \\
\hline
\end{tabular}


Finally, for the dimension that interests us the most in this work, that of the operation "Teaching-learning", we will only retain the skills that have a reduced appearance in teachers (see Figure 1 ).

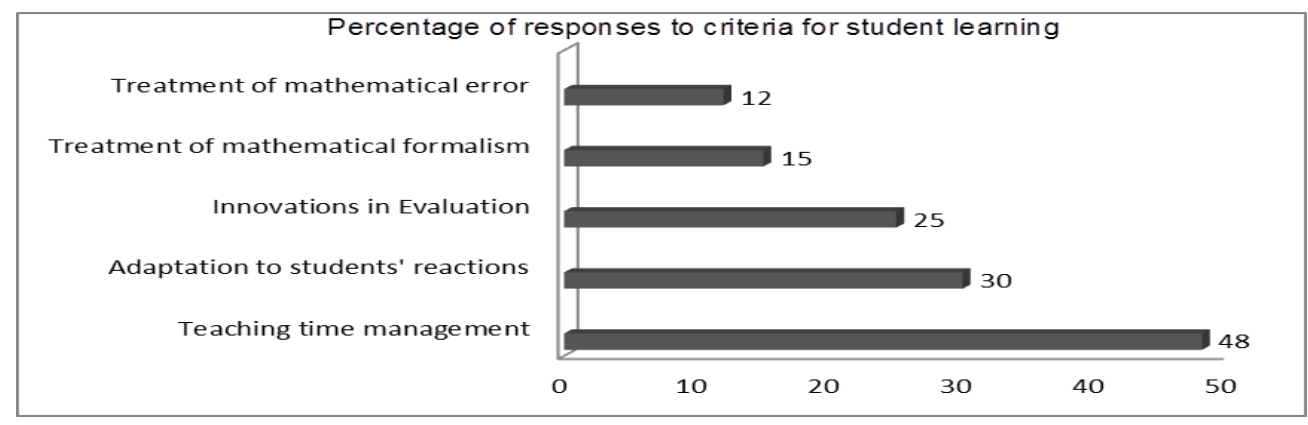

Fig 1: Percentage of responses to criteria for student learning

\section{Second factor analysis}

Let us now analyze the results by crossing the variables "Synthesis" with the respective variables : " First sessions ", " Ancient " and "Posture ", the questions associated with which are respectively : "To make your first sessions at university, - you ? ", " What is your number of years of teaching (counting this year) ?" And " Do you consider yourself a teacher or a researcher?".

By crossing the two variables (First Sessions / Synthesis) see Table 2 below, we note that all teachers (85.7\%) who declare the need for didactic training dont have a real class experience. The reasons given by those who responded by Others (42.9\%) are, generally, those who deliver academic tutoring sessions at continuing education centers or at home.

In the same vein, it can also be seen that the teachers who answer Necessary (50.0\%) or Desirable (45.2\%) are those who have carried out a real class experiment during the preparation of their doctoral theses. It appears that the interest in didactics seems to be linked to the encienté of the exercise of the teaching task if one could consider the last two years of the preparation of the thesis as additional years of teaching.

Table 5. Cross table (First Sessions x Synthesis)

\begin{tabular}{|l|l|c|c|c|c|}
\cline { 2 - 5 } & Not necessary & Desirable & Necessary & \\
\hline & $\begin{array}{l}\text { Took an experience when } \\
\text { you were a PhD student; }\end{array}$ & $4.8 \%$ & $45.2 \%$ & $50.0 \%$ & $100 \%$ \\
\cline { 2 - 6 } & $\begin{array}{l}\text { Imagine sequences when } \\
\text { To make your } \\
\text { first sessions at } \\
\text { university, do } \\
\text { you? }\end{array}$ & $85.7 \%$ & $0.0 \%$ & $14.3 \%$ & $100 \%$ \\
\cline { 2 - 6 } & Other (please specify). & $42.9 \%$ & $0.0 \%$ & $57.1 \%$ & $100 \%$ \\
\cline { 2 - 6 } & TOTAL & $19.6 \%$ & $33.9 \%$ & $46.4 \%$ & $100 \%$ \\
\cline { 2 - 6 } & Dependence is very significant. chi2 = 30, ddl = 4, 1-p = >99\%. & \\
\hline
\end{tabular}


On the other hand, by crossing the two variables (First sessions / Synthesis), see Table 3 below. It is clear that the totality of non-beginner teachers (100\%) dont attach any importance to the introduction of didactics this result is not surprising if we refer to our theoretical framework of clinical didactics where the subject teacher is "supposed to know". We interpret this by the fact that this profound change of the old convictions as well as the teaching doctor is due to the assurance of his new administrative position of a recruited teacher and also of the academic freedom, consequently he apprehends vigorously the operation of teaching-learning into a professional routine.

Table 6 Cross table (Seniority x Synthesis)

\begin{tabular}{|l|c|c|c|c|c|}
\hline \multicolumn{2}{|l|}{ Seniority / Synthesis } & necessary & Not necessary & Desirable & TOTAL \\
\hline $\begin{array}{l}\text { What is your } \\
\text { number of years } \\
\text { of teaching } \\
\text { (counting this } \\
\text { year)? }\end{array}$ & $\begin{array}{c}\text { Between } \\
3-4\end{array}$ & $52.0 \%$ & $10.0 \%$ & $38.0 \%$ & $100 \%$ \\
\hline $\begin{array}{l}\text { Between } \\
5-8\end{array}$ & $0.0 \%$ & $100 \%$ & $0.0 \%$ & $100 \%$ \\
\hline TOTAL & $46.4 \%$ & $19.6 \%$ & $33.9 \%$ & $100 \%$ \\
\hline Dependence is very significant. chi2 = 27, ddl=2, 1-p = >99\%. & \\
\hline
\end{tabular}

It should be noted that our afirst assumptions of teachers who concentrate most on the second research function (77.8\%) assert the non-necessity of didactics. As the following cross table shows:

Table 7. Cross Table (Atittude x Synthesis)

\begin{tabular}{|l|l|l|l|l|l|}
\hline \multicolumn{2}{|l|}{ Atittude / Synthesis } & Necessary & Not necessary & Desirable & TOTAL \\
\hline \multirow{2}{*}{$\begin{array}{l}\text { Do you consider yourself a } \\
\text { teacher or a researcher? }\end{array}$} & Teacher & $53.2 \%$ & $8.5 \%$ & $38.3 \%$ & $100 \%$ \\
\cline { 2 - 7 } & Researcher & $11.1 \%$ & $77.8 \%$ & $11.1 \%$ & $100 \%$ \\
\hline TOTAL & $46.4 \%$ & $19.6 \%$ & $33.9 \%$ & $100 \%$ \\
\hline Dependence is very significant. chi2 = 23, ddl = 2, 1-p $=>99 \%$. & & & \\
\hline
\end{tabular}

Our results certainly dont cover a part of the reality, a reality also shared on an international scale (Langevin, 2007); (Bédard, 2006) and (Ménard \& St-Pierre, 2014). Overall, our survey tries to situate the process issues of learning in the context of a university's postulate for teaching on learning. 


\section{Conclusion}

We try to account for the importance of the conception of a pedagogical project at the university which makes it possible to become aware, in terms of didactics, of the professional aspects of newly recruited teachers to this institution without prior training in the teaching profession. We have included this state of affairs in a framework of necessity for the introduction of didactics to higher education, with a view to promoting learning rather than teaching. In order to identify teachers' personal relationships, we carried out a survey using a questionnaire oriented towards teachers of mathematics, whose analysis enabled us, through clinical teaching, to help the teacher to think about a practice with effects on a training system designed to produce rigorous scientific knowledge.

We are betting on the aspect of the teacher's profession, in its dimension of self-employment, so that the professor engages in a reflective professional practice which would allow him to question his planning habits and mathematical knowledge management. These remarks and reflections will contribute gently to the consciousness, at the organizational level, that the university in its classical structure, where the task of learning is assumed in a personal way, do not help to improve student learning, especially in mathematics.

\section{REFERENCES}

1. BÉDARD, D. (2006). Enseigner autrement, oui mais pourquoi et comment ? Le cas d'un cours universitaire du premier cycle. Dans N. Rege Collet et M. Romainville (dir.), La pratique enseignante en mutation à l'université (pp. 83-101). Bruxelles : De Boeck.

2. BURN , K., CHILDS, A. et Mc NICOLL, J. (2007). The potential and challenges for student teachers' learning of subject-specific pedagogical knowledge within secondary school subject departments. The Curriculum Journal, 18(4), 429-445.

3. GESS-NEWSOME J \& CARLSON J (2013) The PCK Summit Consensus Model and Definition of Pedagogical Content Knowledge. In the Symposium "Reports from the Pedagogical Content Knowledge (PCK) Summit, ESERA Conference 2013, September.

4. HASHWEH, M. Z. (2005). Teacher pedagogical constructions : A reconfiguration of pedagogical content knowledge. Teachers and Teaching: Theory and Practice, 11(3), 273-292.

5. TERRISSE, A. (1999). La question du rapport au savoir dans le processus d'enseignement- apprentissage : le point de vue de la clinique. (pp. 62-87). Amiens : Carrefours de l'éducation 7.

6. SHULMAN, L. (1986). Those Who Understand: Knowledge Growth in Teaching. Educational Researcher, 15 (2) (1986), pp. 4-14.

7. SHULMAN, L. (1987). Knowledge and Teaching: Foundations of the New Reform. Harvard Educational Review, 57 (1) (1987), pp. 1-22.

8. PARK, S. \& OLIVER, J. S. (2008). Revisiting the conceptualisation of pedagogical content knowledge (PCK): PCK as a conceptual tool to understand teachers as professionals. Research Science Education, 38(3), 261-284.

9. KIND V (2009) Pedagogical content knowledge in science education: perspectives and potential for progress. Studies in Science Education 45(1): 169-204

10. LANGEVIN, L. (2007). Formation et soutien à l'enseignement universitaire : des constats et des exemples pour inspirer l'action. Sainte-Foy, Québec : Presses de l'Université du Québec. 
11. LOIZON, D., MARGNES, E., TERRISSE, A. (2008). La transmission des savoirs: le savoir personnel de I'enseignant. Paris: Revue Savoirs n8.

12. MÉNARD, L. \& St-PIERRE, L. (2014). Se former à la pédagogie de l'enseignement supérieur. Montréal : Chenelière éducation.

\section{Appendix}

\section{University Teacher Practice}

Thank you for having answered to this questionnaire

Teacher Attributes

1. What is your number of years of teaching (counting this year) ?.....

$$
\text { between } 3-4 \ldots \quad \text { between } 5-8 \ldots \quad \text { between } 9-11
$$

2. To make your first sessions at the university, you have :......... Imagine sequences when you were a student $\ldots \quad$ Took an experience when you were a PhD student... Other

3. Do you consider yourself to be a teacher or searcher ?.................. teacher ... Researcher

4. In your opinion, is it enough to know the discipline to teach it ?.... Yes... No

5. You are satisfied with the progress of the sessions of tutorial classes (TC) ?.......... Yes ..... No

Dimension 1: Exchange Teacher-Teacher

6. To make your first sessions at university, have you contacted any of your colleagues experienced ?... $\ldots . . . . . .$. Yes No

7. Speak to your colleague about the program to teach ?........... Yes No

8. Does your department organize meetings to talk about the program to teach ? .......... Yes No

9. Do you ask one of your colleagues for a course ?.... Yes $\quad$ No

\section{Dimension 2: Exchange Teacher-Student}

10. Do you encourage your students to ask questions ?........... Yes No

11. Do you feel your students are following you? ........................ Yes No

12. Do you allow enough time for students to search for solutions ? ... Yes No

13. Do you have any idea about the errors of your students ?.... Yes No

14. To prepare your course, do you use your old documentation as well as student? ....... Yes No

15. When developing a course, do you set the point where you want to stop? ......... Yes No 16. Do you give comments when solving exercises ?........... Yes No 
17. Do you always keep the same content courses from past years ? . Yes No

18. Do you pass the students on the board $? \ldots \ldots \ldots \ldots \ldots \ldots \ldots$ Yes No

19. Do you think that the time devoted to correction is enough ? ...... Yes No

20. Do you know the content of the discipline in secondary school ?...... Yes No A little

21. Do you happen to be "blocking" on the board?........ Yes No

22. When developing TC, do you respect the order appearing in the copy of exercises? .......Yes No 23. When developing courses, do you consider error remediation?...... Yes No

24. Do you have any idea about the chapters programs which pose difficulties for students? Yes

25. When you do a course, do you like better? .....

When there is formalism When there is heuristics When there is empiricism

Need for didactics

26.If one can call didactics the study of the stakes underlying all of these issues, do you believe that before exercising the profession of teacher, a training course in didactics of the discipline is :

Necessary Not necessary Desirable 